\title{
Finite-time stable of time-varying delay Distributed Parameter Systems with input saturation via Periodically Intermittent Control
}

\author{
Wenhua Xia ${ }^{1}$, Yiping Luo $^{1}$, Bifeng Zhou ${ }^{2}$, and Zhujun Wang ${ }^{1}$ \\ ${ }^{1}$ Hunan Institute of Engineering \\ ${ }^{2}$ Hunan electrical college of technology
}

September 24, 2021

\begin{abstract}
A class of time-varying delay distributed parameter systems with input saturation is investigated in this paper. The periodic intermittent control method is adopted to make the system stable in finite time, improve the control performance of the system, and save on control cost. A periodic intermittent controller combined saturated input is designed to ensure the stability of the proposed system in finite time. Lyapunov-Krasoviskii stability theory and Matrix inequality techniques are used to analyze the finite-time stability of the system, and sufficient conditions for the system to be stable in finite time are obtained. Finally, the correctness of the theorems is verified by simulation experiments.
\end{abstract}

\section{Hosted file}

manuscript.pdf available at https://authorea.com/users/435858/articles/538594-finite-timestable-of-time-varying-delay-distributed-parameter-systems-with-input-saturation-viaperiodically-intermittent-control 

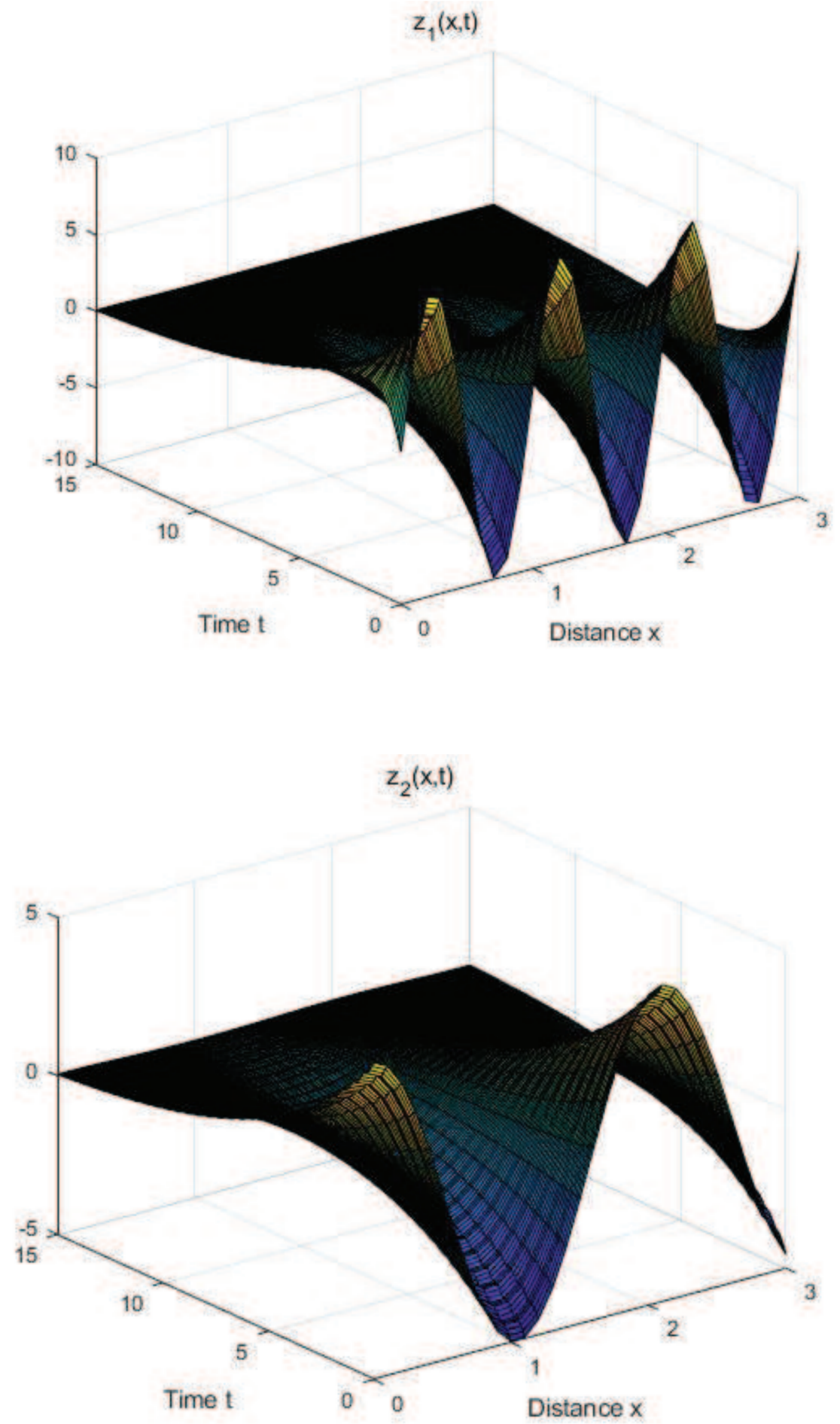

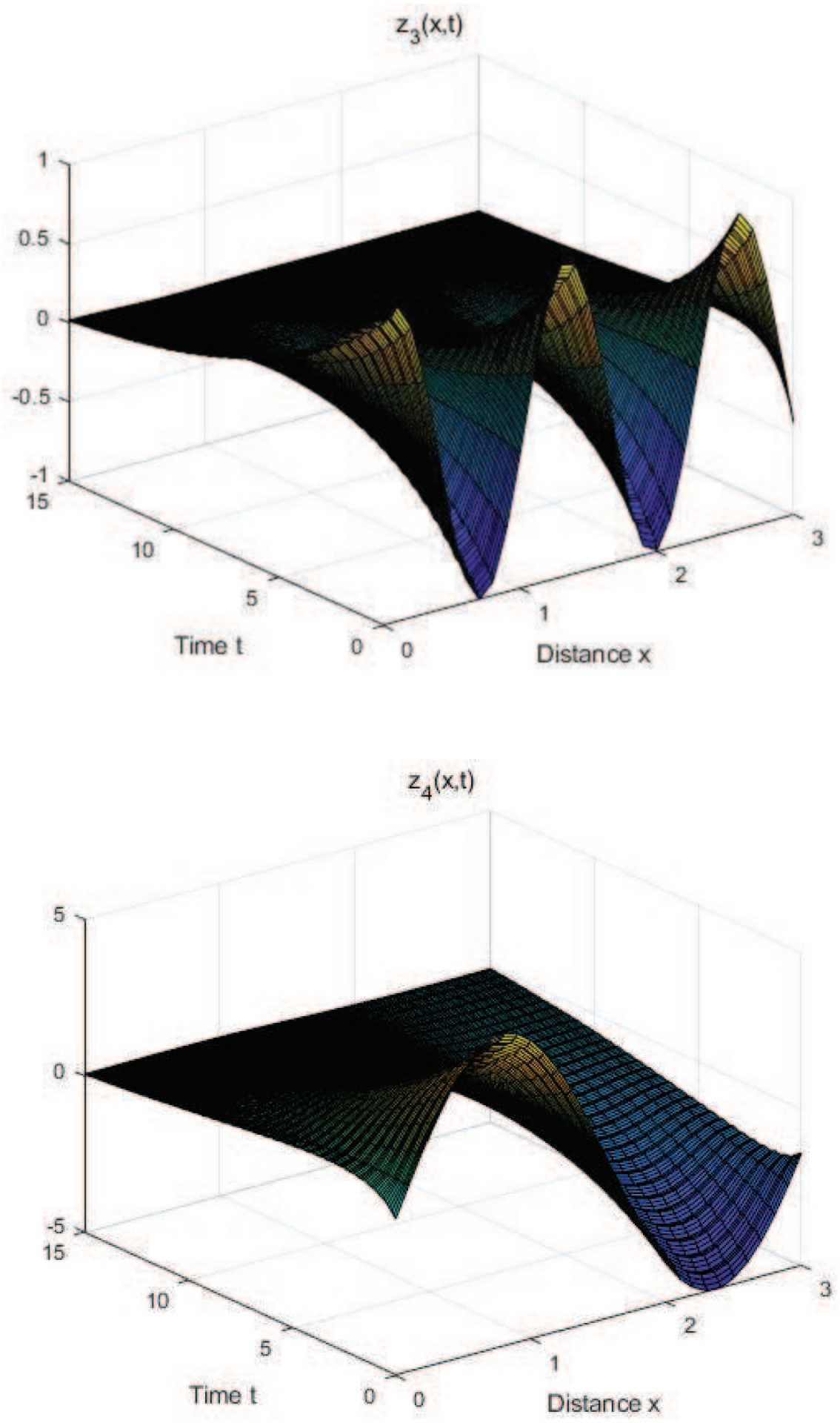

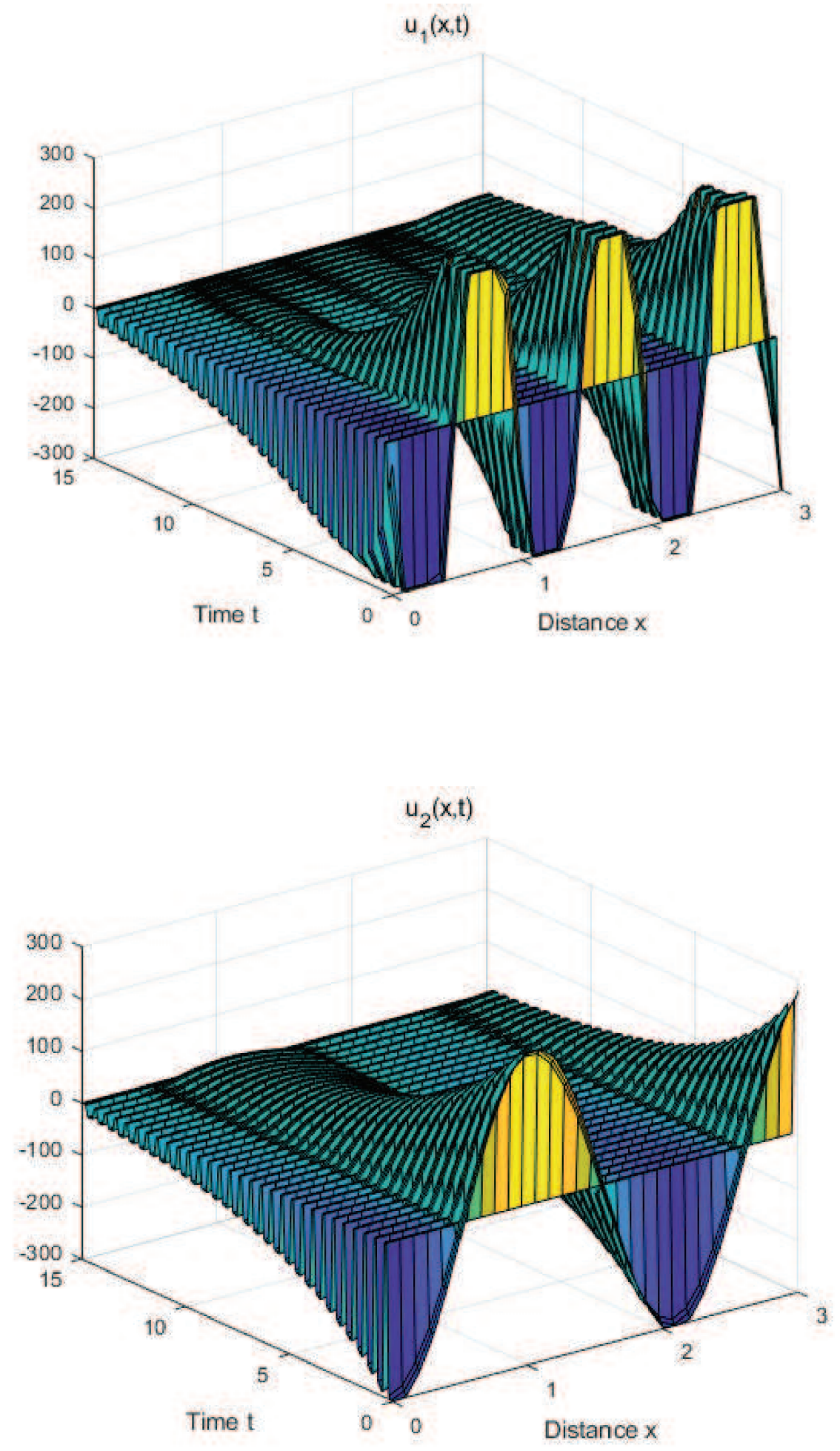

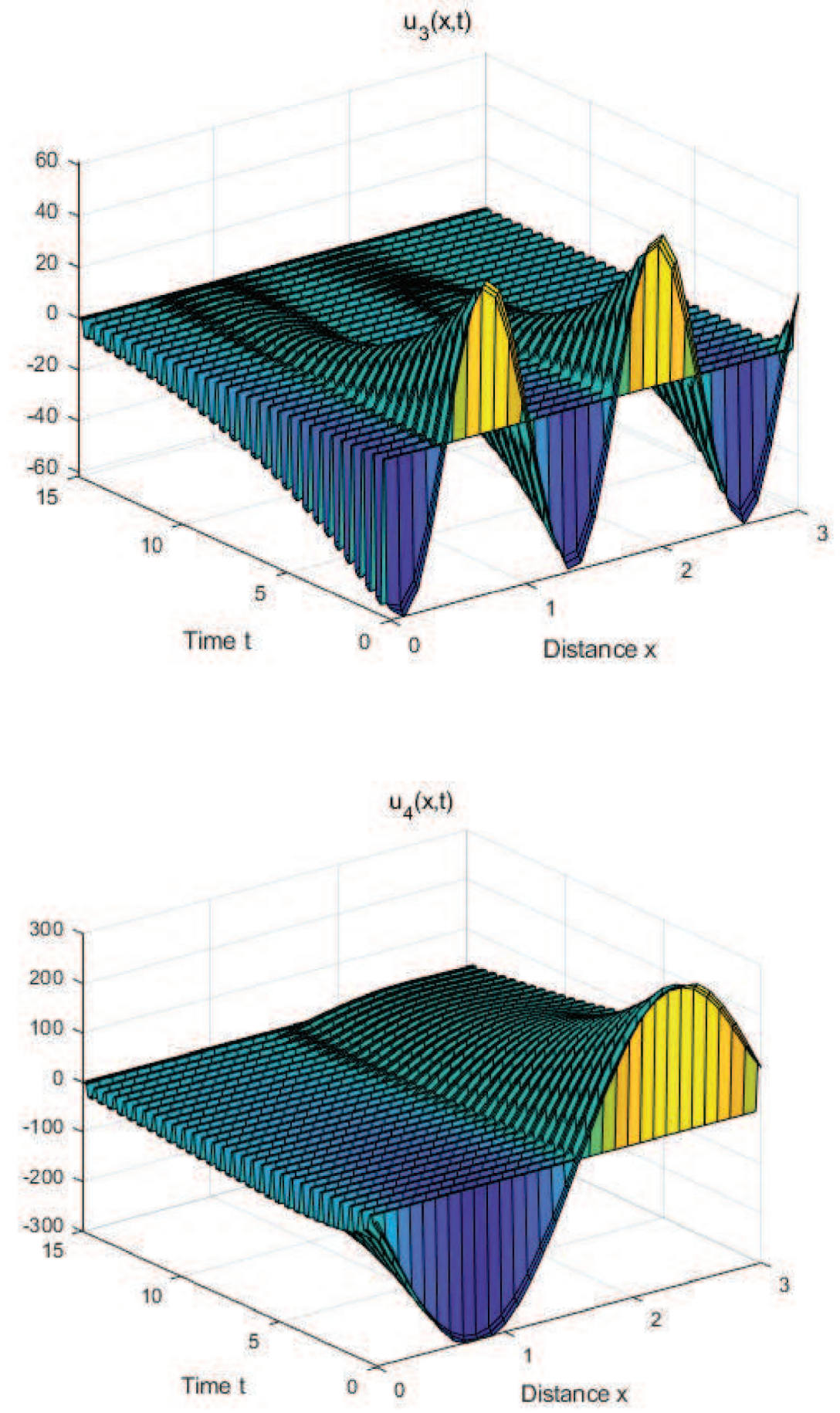